\title{
Oxygen-enhanced combustion in waste incineration: economic and environmental considerations
}

\author{
N. Verdone, G. Liuzzo, P. De Filippis \& F. Mazzoni \\ Department of Chemical Engineering Materials Environment, \\ University of Rome "La Sapienza", Italy
}

\begin{abstract}
In this paper the benefits attainable by replacing atmospheric air with oxygen enriched air in waste incineration processes are examined. Technical, economical and environmental aspects are all discussed on the basis of the results of process simulations performed by using the PRO/II-Provision v. 7.01 flowsheeting simulator (SimSci-Esscor). The simulations were carried out modelling an incineration plant equipped with a heat recovery section and a flue gas recirculation into the combustion chamber. The study is parameterized varying the thermal input to the plant (waste flow rate), the temperature set in the combustion chamber, the grade of enrichment in oxygen of the oxidizer and the price of the generated electric power. Results show that higher heat recovery efficiencies, lower fixed costs and decreased emissions of atmospheric pollutants are obtained when enriched air is utilized.
\end{abstract}

Keywords: waste incineration, oxygen-enhanced combustion, waste-to-energy.

\section{Introduction}

The use of oxygen enriched air has become an accepted practice in the field of chemical oxidation and combustion processes, typically in the steel, iron, glass, cement, pulp and paper, and petrochemical industries. The main benefits in the use of oxygen enriched air as an oxidizer have been described by several authors and can be summarized in the following points: (1) increase of flame temperature and stability, enhancing heat transfer efficiency, (2) increase in the combustion reaction rate due to the higher oxygen partial pressure, (3) prevention of soot formation, (4) reduction of fuel flow rate and flue gas generation. 
Comprehensive reviews can be found in Kobayashi [1] and more recently in Baukal [2]. Even if the incineration process should substantially benefit from all of these advantages, as discussed in Beaudoin et al. [3], Acharya and Schafer [4], Melo et al. [5] and Gohlke and Busch [6], enriched air is not so extensively used, primarily due to the operative tradition in this field and to certain system complexities, but also due to the associated economic considerations with the cost of oxygen. In the future, however, oxygen is expected to play a prominent role in this industry since waste disposal costs are increasing while oxygen production cost is decreasing due to a deeper understanding and optimization of both cryogenic and non cryogenic gas separation technologies.

The most attractive benefits associated with the use of enriched air in waste combustion concern the increased waste processing capacity, steam production and thermal efficiency, the reduced air pollution control devices (APCD) size and pollutants emission factors and the increased destruction and removal efficiency (DRE). Oxygen enrichment can be valuable in both new facilities and retrofit situations. For a new facility, oxygen enrichment allows more compact equipment design with associated lower capital cost. In a retrofit situation, oxygen enrichment can improve both the combustor performance (plant capacity and destruction efficiency) and the environmental performance (lower emission factors and ash quality). The aim of this paper is to verify the potential use of enriched air in waste incineration through a valuation of the technical, economic and environmental aspects.

\section{Enriched air waste combustion}

The use of enriched air in waste incineration causes the flue gas specific production to decrease. This effect is more and more important as the enrichment factor increases, oxidizer excess being equal. The flue gas volumetric specific flow rate, $V_{S}\left[\mathrm{Nm}^{3} / \mathrm{kg}_{\mathrm{WASTE}}\right]$, generated in the combustion of a waste can be expressed with a sufficient approximation (waste moisture is not considered) as:

$$
\begin{aligned}
V_{S}=0.02241 \times 10 & \left(\frac{C}{12}+\frac{H}{2}\right)+0.02241\left(1-\frac{O_{C}}{100}\right) 10\left(\frac{C}{12}+\frac{H}{4}-\frac{O}{32}\right) \frac{100}{O_{C}}+ \\
& +0.02241 \frac{e}{100} 10\left(\frac{C}{12}+\frac{H}{4}-\frac{O}{32}\right) \frac{100}{O_{C}}
\end{aligned}
$$

where $C, H$ and $O$ are the weight percentages of carbon, oxygen and hydrogen in the waste, respectively, $O_{C}$ is the oxygen content in the oxidizer [\%v] and $e$ the oxidizer excess [\%]. In eqn (1) the specific volumetric flue gas production is computed by three terms which in turn account for the stoichiometric combustion with pure oxygen, the contribution due to the nitrogen content in the oxidizer and the oxidizer excess. From eqn (1) it is easily verified that the use of pure oxygen in the waste thermal treatment process decreases the specific flue gas flow rate of approximately four times with respect to the use of atmospheric air. Furthermore, the average oxygen concentration increases too. If the volumetric percentage of free oxygen in humid flue gas is set equal to $6 \%$ (a 
value that must be guaranteed by the environmental regulation), the average oxygen content is equal to $13.5 \%$ in the case of atmospheric air and equal to $\left(O_{c}\right.$ $+6) / 2$ in the case of enriched air, so half a point higher for each point of difference between $O_{c}$ and $21 \%$.

A major consequence of the oxygen-enhanced combustion concerns the heat recovery efficiency, $\eta_{t}$, defined as:

$$
\eta_{t}=\frac{L H V\left(1-\eta_{d}\right)-V_{S} h_{f}}{L H V}
$$

where $L H V$ is the waste lower heat value $\left[\mathrm{kJ} / \mathrm{kg}_{\mathrm{WASTE}}\right], h_{f}$ the specific flue gas enthalpy $\left[\mathrm{kJ} / \mathrm{Nm}^{3}\right]$ at the boiler exit, and $\eta_{d}$ accounts for the heat dispersion from the plant into the environment. In eqn (2) the numerator represents the difference between the heat made available from the combustion and the loss of enthalpy associated to the flue gas leaving the boiler. From eqn (2) it can be observed that, increasing the enrichment factor and keeping constant the flue gas temperature and enthalpy at the boiler outlet (the effect of this last approximation has been valued in Liuzzo et al. [7]), the thermal efficiency increases too, since the heat loss associated with the specific flue gas flow rate leaving the boiler decreases.

Furthermore, enriched air combustion has the advantage to reduce the pollutants emission factors. In fact, while the formed pollutants concentrations are quite different in the two processes upstream the ACPD section, they become the same downstream this section, being the final pollutant content dependent on the APCD performances, but not on the inlet value. Accordingly, it is quite evident that the increase of the enrichment factor and the consequent decrease of the volumetric specific flue gas flow rate produce a proportional decrease of the emission factors of all the considered pollutants.

A last consideration regards the revamping of existing plants, when the capacity of the combustion section is maintained as in the original project. The flue gas residence time in both the combustion section and the APCDs section increases due to the lower volumetric specific flue gas flow rate. As a consequence, a higher degree of completeness of the oxidation reactions decreasing the products of incomplete combustion (PICs) content and a higher effectiveness in the gas treatment section will be achieved.

\section{Flowsheet simulation of the incineration plant}

To verify the use of enriched air in waste incineration plants and to quantify the above considerations, a number of simulations were carried out in the PROIIProvision (Simsci-Esscor, v. 7.01) environment. The simulated plant consists in a mass burning waste incineration plant equipped with an adiabatic combustion chamber and a flue gas recirculation into the combustion chamber. Two control loops set the temperature in combustion chamber and the free oxygen content in the flue gas at the boiler exit $(6 \% \mathrm{v}$ on wet basis, according to current legislation). Power is generated by a power cycle with two-bleed regenerative feed water heating. The gas cleaning section modelling is limited to the extent required for pressure drop and pumping power estimation. For all the considered cases, the simulations were carried out assuming a typical municipal solid waste ( $L H V$ 
$10166 \mathrm{~kJ} / \mathrm{kg}$, water $25.5 \% \mathrm{w}$, ash $24.40 \% \mathrm{w}, \mathrm{C} 25.60 \% \mathrm{w}, \mathrm{H} 3.40 \% \mathrm{w}, \mathrm{O}$ $20.30 \% \mathrm{w}, \mathrm{N} 0.50 \% \mathrm{w}, \mathrm{S} 0.15 \% \mathrm{w}, \mathrm{Cl} 0.45 \% \mathrm{w})$. The processing capacity was varied in the range $10-50 \mathrm{t} / \mathrm{h}$ and the oxidizer oxygen content in the range $21 \% \mathrm{v}$ - $100 \%$ v. Finally, three different temperatures were set in the combustion chamber, $T_{c}: 850,950$ and $1200{ }^{\circ} \mathrm{C}$. In the following only the main results helpful for the considerations of interest are reported and referred to a plant capacity of $10 \mathrm{t} / \mathrm{h}$, the specific quantities being invariant and the absolute quantities scaling proportionally. A detailed description of the simulated plant and the basic assumptions in the calculation can be found in Liuzzo et al. [7].

The flow rate of the emitted flue gas is practically unrelated to the combustion temperature, being the flue gas volumetric specific flow rate in the simulated scheme dependent exclusively on the oxidizer composition and excess. This last quantity is unrelated to the combustion temperature but exclusively depends on the free oxygen content $(6 \% \mathrm{v})$ set downstream the combustion process. Furthermore, the flow rate decreases as the enrichment factor increases: shifting from atmospheric air to pure oxygen, the emitted flue gas flow rate drops by a factor of 3.5 (temperatures set in combustion chamber being equal). On the contrary, the recirculated flue gas flow rate varies with the combustion temperature, increasing as this temperature decreases, and with the air enrichment factor (Figure 1).

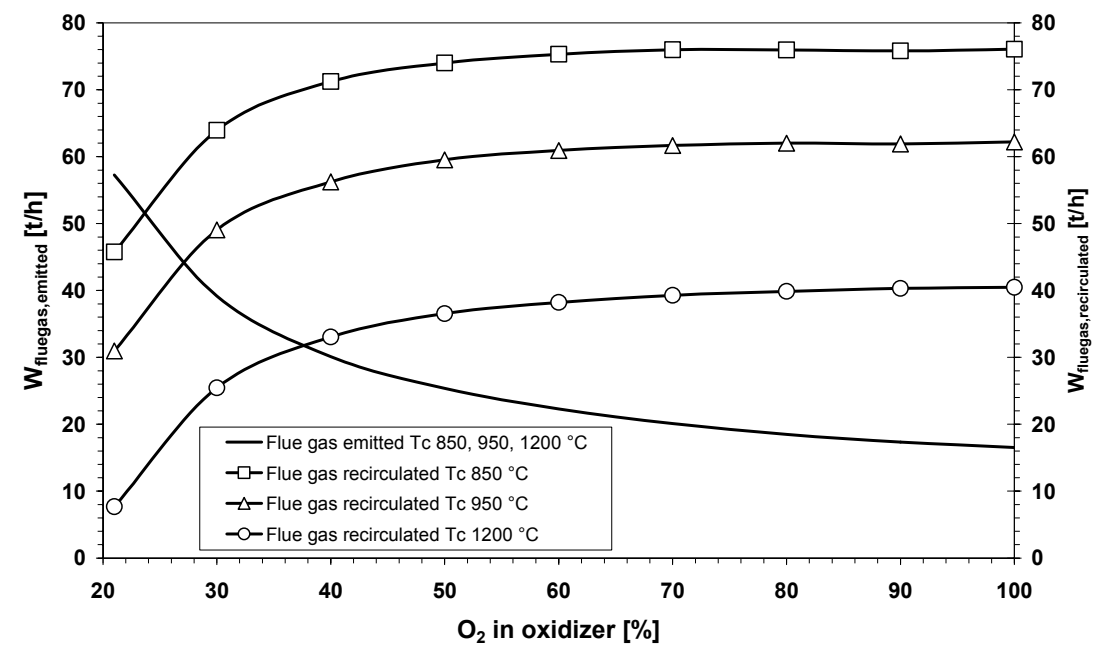

Figure 1: Emitted and recirculated flue gas flow rate vs. air enrichment.

The net energy conversion efficiency in recovering thermal power to electric power, $\eta_{e e}$, shows a slight increase at increased combustion temperature (at constant oxidizer enrichment factor), and a substantial dependence on the content of oxygen in the oxidizer, with an average increase of $12 \%$ when pure oxygen is used. This effect depends on the opposite influence wielded by the progressive decline of the flue gas flow rate and enhancement of the associated specific enthalpy (related to the water vapour content increase, Liuzzo et al. [7]) (Figure 2). 


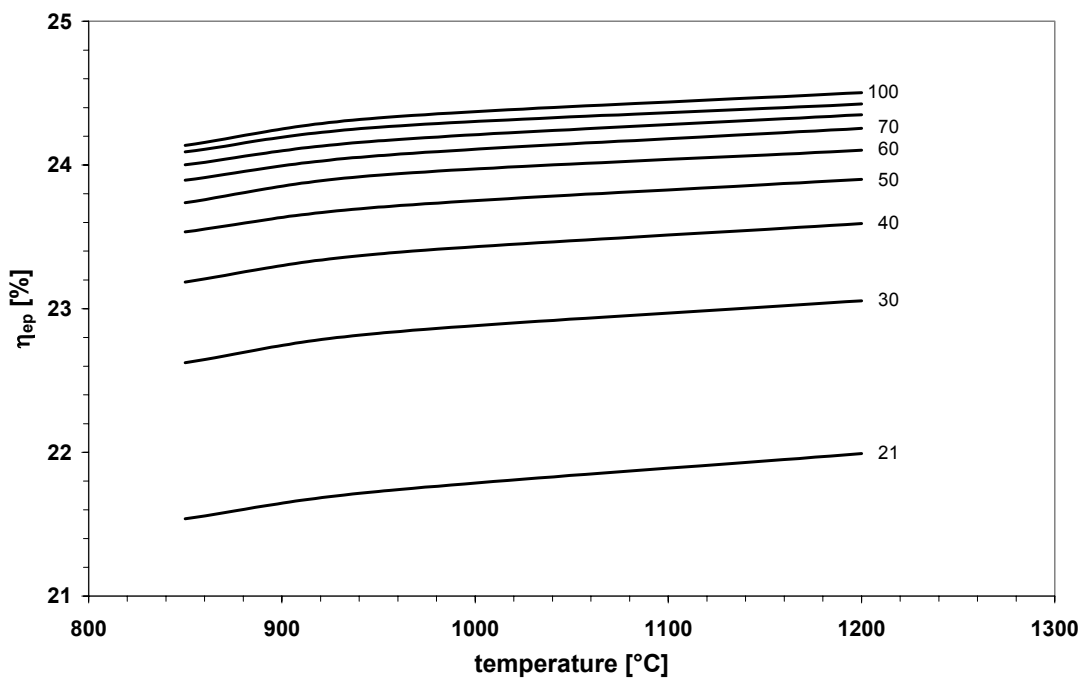

Figure 2: Net electric power generation efficiency vs. temperature in combustion chamber (parameter $\% \mathrm{O}_{2}$ in oxidizer).

\section{Economic evaluation}

In order to evaluate from an economic point of view the use of an oxygen enriched oxidizer in waste-to-energy incineration plants, the following items were taken into account at fixed plant capacities: (1) the plant cost and its impact on the operating cost through an annualization factor; (2) the cost associated with the consumption of oxygen enriched air; (3) the revenue associated with the selling of the net electric power generation.

The plant cost should be found to decrease as the air enrichment factor increases due to the envisaged size reduction of the APDCs section, which is proportional to the scaled emitted flue gas flow rates. The oxidizer cost does obviously increase as the enrichment factor increases. The revenue associated to the selling of the net electric power also increases as the oxidizer enrichment factor increases, due to the concurrent increase of the net power production efficiency.

The economic evaluation was performed with respect to an assumed plant operating factor of $7000 \mathrm{~h} / \mathrm{y}$.

Recent constructions of MSW incineration plants supplied with atmospheric air indicate, for a $1000 \mathrm{t} / \mathrm{d}$ plant capacity assumed as reference, a specific plant cost of $155 \mathrm{k} € / \mathrm{t} / \mathrm{d}$ (Iaboni and De Stefanis [8]). With the assumption that this cost scales with the plant capacity according to a 0.7 exponent, the plant cost function $C_{P}[\mathrm{M} €]$ can be expressed as:

$$
C_{P}=C_{0}\left(\frac{Q}{Q_{0}}\right)^{0.7}=155\left(\frac{Q}{1000}\right)^{0.7}
$$


where $C_{0}$ is the cost of the reference plant [M€], $Q$ the plant capacity [t/d] and $Q_{0}$ the reference plant capacity $[\mathrm{t} / \mathrm{d}]$. A further assumption was made in order to take into account the impact of the APCDs section on the total plant cost. A fixed contribution equal to $30 \%$ of the total cost was assumed. Furthermore, in the case of plants supplied with enriched air, it was assumed that the cost of the APCDs section scales with the flue gas flow rate rose at a 0.7 exponent. With these assumptions, the plant cost, $C_{P e a}[\mathrm{M} €]$, can be valued as implicit function of the air enrichment factor according to

$$
C_{\text {Pea }}=0.7 C_{P}+0.3 C_{P}\left(\frac{V_{\text {Fea }}}{V_{\text {Fair }}}\right)^{0.7}
$$

where $V_{F e a}$ and $V_{\text {Fair }}\left[\mathrm{Nm}^{3} / \mathrm{h}\right]$ are the flue gas flow rates generated by the process supplied with enriched air and atmospheric air, respectively. The impact of the plant cost expressed by eqn (4) on the annual operating cost was valued through an annualization factor $A_{f}$ fixed in the range $0.07-0.13$, to take into account the remarkable variability in the money cost with reference to the possible facilitations scheduled for this class of plants. With these considerations, the impact of the plant cost, $C_{P S}\left[€ / \mathrm{kg}_{\mathrm{WASTE}}\right]$, on the specific cost of the waste thermal treatment was computed through the relationship

$$
C_{P S}=\frac{C_{P e a} A_{f} \times 10^{6}}{1000 Q \times 365 \times \frac{7000}{8760}}
$$

where all the considered quantities have been already defined.

It can be easily observed that the impact of the plant cost on the specific waste treatment cost noticeably decreases as the oxidizer enrichment factor increases. As an example, considering a $A_{f}$ of 0.13 and a low plant capacity $(240 \mathrm{t} / \mathrm{d}), C_{P S}$ varies from 0.11 to $0.09 € / \mathrm{kg}_{\text {WASTE }}$ shifting from the use of air to pure oxygen, while assuming 0.07 for $C_{r}$ and a high plant capacity $(960 \mathrm{t} / \mathrm{d})$ the variation is limited in the range $0.04-0.03 € / \mathrm{kg}_{\mathrm{WASTE}}$.

The cost of the oxygen was estimated with the assumption that, for the oxidizer flow rates needed for incineration plants of various hundred $t / d$ capacity, the cheapest way to support the requirements is the production of pure oxygen and the formulation of the oxidizer at the chosen enrichment by mixing with atmospheric air. In these cases, technical gas production companies generally assure the supply of oxygen at competitive costs, operating their own dedicated production plants. In the present study an oxygen cost on volumetric basis of $0.08 € / \mathrm{Nm}^{3}$ was assumed on the basis of a long period agreement. The specific requirement of pure oxygen for each of the considered cases was estimated from the simulation outputs. The resulting specific costs for oxygen consumption referred to the mass unity of treated waste, $C_{O 2}\left[\left[€ / \mathrm{kg}_{\mathrm{WASTE}}\right]\right.$, are reported in Table 1 as function of the enrichment factor.

The revenue from the sale of the net produced electric power depends on the unit price assumed. In Italy such a price is at the moment under definition, so a parametric valuation was performed having assumed selling prices in the range $0.08-0.15 € / \mathrm{kWh}$. 
Table 1: The impact of oxygen cost on the waste treatment cost.

\begin{tabular}{cccccccccc}
\hline \multicolumn{10}{c}{$\mathrm{O}_{2}$ content $(\%$ v.) in oxidizer } \\
\hline$C_{\text {O2 }}$ & 21 & 30 & 40 & 50 & 60 & 70 & 80 & 90 & 100 \\
{$\left[€ / \mathrm{kg}_{\text {WASTE }}\right]$} & 0.00 & 0.02 & 0.03 & 0.04 & 0.04 & 0.04 & 0.04 & 0.05 & 0.05 \\
\hline
\end{tabular}

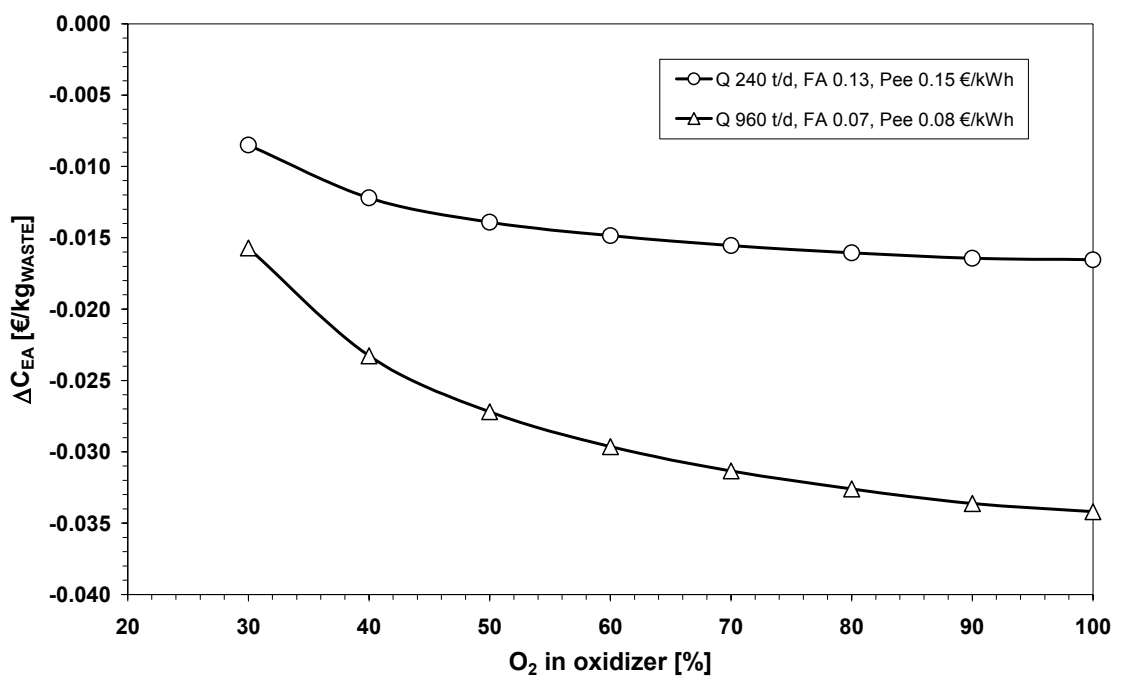

Figure 3: $\Delta$ cost vs. air enrichment.

The specific revenue referred to the mass unit of treated waste, $R_{S e p}$ $\left[\left[€ / \mathrm{kg}_{\text {WASTE }}\right]\right.$, can be easily calculated by

$$
R_{\text {Sep }}=P_{e e} \times P_{\text {See }}
$$

where $P_{e e}[€ / \mathrm{kWh}]$ is the electric power selling price and $P_{S e e}\left[\mathrm{kWh} / \mathrm{kg}_{\text {WASTE }}\right]$ the net specific electric power generation. As can be noted from Figure 2, the net electric power specific production weakly depends on the temperature value set in the combustion chamber.

The economic comparison between an incineration plant supplied with atmospheric air and a plant of same capacity but supplied with enriched air can be simply performed as function of the air enrichment factor defining a cost comparison factor $\Delta C_{E A}$ (extra cost). This factor is the sum of the difference of the three cost items previously defined and calculated with reference to the same cost values estimated in the case of atmospheric air supply, according to

$$
\Delta C_{E A}=\Delta R_{S e p}-\Delta C_{O_{2}}+\Delta C_{P S}
$$

The cost comparison factor $\Delta C_{E A}$ is reported as function of the air enrichment factor in Figure 3 only for the maximum and minimum limiting cases. It can be observed that the oxygen enriched oxidizer produces a higher specific waste 
treatment cost which increases as the enrichment factor increases in all the range of the parameters set for the economic analysis.

The extra cost is minimum when the values of the three parameters set in the analysis are most favourable $\left(P_{e e}=0.015 € / \mathrm{kWh}, A_{f}=0.13, Q=240 \mathrm{t} / \mathrm{g}\right)$, that is for the lowest plant capacity and the highest values of the electric power selling price and of the money cost, being in the range of $0.008 € / \mathrm{kg}_{\text {WASTE }}$ with $O_{C} 30 \%$ and $0.016 € / \mathrm{kg}_{\text {WASTE }}$ with $O_{c} 100 \%$. Otherwise, the extra cost is maximum when the values of the three considered parameters are most unfavourable $\left(P_{e e}=0.008\right.$ $\left.€ / \mathrm{kWh}, A_{f}=0.07, Q=960 \mathrm{t} / \mathrm{g}\right)$, being in the range of $0.015 € / \mathrm{kg}_{\text {WASTE }}$ with $O_{C}$ $30 \%$ and $0.034 € / \mathrm{kg}_{\text {WASTE }}$ with $O_{c} 100 \%$.

\section{Environmental evaluation}

In waste incineration careful consideration should be given on the noticeable public concern with respect to the environmental impact of the atmospheric pollutant emissions. Despite the higher waste treatment specific cost due to the impact of the prominent oxygen cost, the use of enriched air allows to achieve several environmental benefits.

A first important benefit follows from the lower specific emissions (referred to the mass unit of treated waste), which characterize a plant supplied with enriched air. In fact, as previously reported, the flow rate of the emitted flue gas decreases as the oxidizer enrichment factor increases. In the realistic assumption that the effective pollutant concentrations in the flue gas at the stack depend only on the performance of the APCDs, the pollutant emissions are proportional to the flue gas flow rate. When this assumptions hold, as the specific flue gas generation decreases, although in non linear fashion, of about 4 times when the oxidizer oxygen content varies from $21 \%$ to $100 \%$ (irrespective of the temperature value set in the combustion chamber, Figure 1), at the same extent the emissions of all the considered pollutants should decrease. An approximate quantification of this benefit can be valued considering actual concentrations of the main pollutants, $C_{e}\left[\mathrm{mg} / \mathrm{Nm}^{3}\right]$, coincident with the emission limits enforced by the EC environmental regulation. In Table 2 the emission factors, $E_{\text {Fair }}$ and $E_{F e a}\left[\mathrm{~g} / \mathrm{kg}_{\text {WASTE}}\right]$, calculated for the two extreme cases of $O_{c} 21 \%$ and $100 \%$, are reported.

A second environment benefit achieved with the use of enriched air consists in a lower content in the flue gas at the boiler exit of products of incomplete combustion such as carbon monoxide, volatile organic compounds, aromatic

Table 2: $\quad$ Comparison of the emission factors.

\begin{tabular}{|c|c|c|c|}
\hline Pollutant & $C_{e}\left[\mathrm{mg} / \mathrm{Nm}^{3}\right]$ & $E_{\text {Fair }}\left[\mathrm{g} / \mathrm{kg}_{\text {WASTE }}\right]$ & $E_{\text {Fea }}\left[\mathrm{g} / \mathrm{kg}_{\text {WASTE }}\right]$ \\
\hline $\mathrm{CO}$ & 50 & 0.228 & 0.065 \\
\hline $\mathrm{SO}_{2}$ & 50 & 0.228 & 0.065 \\
\hline $\mathrm{NO}_{2}$ & 200 & 0.913 & 0.260 \\
\hline $\mathrm{VOC}$ & 10 & 0.046 & 0.013 \\
\hline $\mathrm{TSP}$ & 10 & 0.046 & 0.013 \\
\hline
\end{tabular}


polycyclic hydrocarbons and chlorinated organic micropollutans. These results can be obtained due to the higher average content in oxygen, which enhances the oxidation rate.

A last consideration regards the case of revamping of existing plant when the plant treatment capacity is hold constant. The use of enriched air allows the increase of the residence times in both the combustion and the APCD sections. This characteristic assures the completeness of the oxidation reactions at a major extent and reduces the concentration of PIC in the flue gas produced in the combustion process. Furthermore, the increased residence time in the APCD section enhances the effectiveness of the flue gas cleaning system with reference to all the pollutants considered in the design.

\section{Conclusions}

The economic evaluation of the oxygen enriched oxidizer use in the thermal treatment of wastes has quantified the net disadvantage in the range 0.016 $0.035 € / \mathrm{kg}_{\text {WASTE}}$. This rising specific treatment cost is mainly due to the impact of the pure oxygen production cost, which is never compensated by the decreasing specific plant cost and by the increasing revenue in electric power selling. The extent of the economic disadvantage in the estimated range results from the different influence of the three major considered parameters (plant capacity, capital recovery factor and price of electric power).

However, when environmental benefits are considered, the use of enriched air allows reducing the pollutants emission factors up to a $75 \%$ roughly when pure oxygen is used. Moreover, a further benefit quantified as about $12 \%$ can be envisaged when the increased efficiency in power generation is considered. The power specific production steps up from 0.61 to $0.69 \mathrm{kWh} / \mathrm{kg}_{\text {WASTE }}$ supplying the plant with air or pure oxygen, respectively.

It is difficult to express a definitive opinion about the opportunity to privilege the economic disadvantages or the environmental benefits in considering enriched air as oxidizer in waste-to-energy incinerators. However, an specific extra cost quantified in few ten cent€ is relatively reasonable if compared with the full disposal specific cost of hundred cent€ and could lead to a deeper analysis of the reflections here exposed and to consider that the environmental benefits should not be a priori disregarded basing only on economics.

Finally, the main objective in the design of incineration plants environmentally sound should consist not only in the development of more and more efficient and expensive flue gas cleaning technologies, but in selecting those techniques that, optimizing the heat recovery efficiency, maximize both the economic and environmental benefits. The use of oxygen enriched oxidizer summarizes both these characteristics.

\section{References}

[1] Kobayashi H., Oxygen enriched combustion system performance study. DOE Report, DOE/ID/12597-1, 1987. 
[2] Baukal C.E., (ed). Oxygen-enhanced Combustion, CRC Press, 1998.

[3] Beaudoin P., Charon O., Plessier R., Haines A., Schmidt A., The use of pure oxygen in incineration processes, laboratory and pilot-scale experiments, modelling, and industrial applications. Proc. of the $13^{\text {th }}$ International Incineration Conference, pp. 419-423, 1994.

[4] Acharya P., Schafer L.L., Consider Oxygen-Based Combustion for waste Incineration, Chemical Engineering Progress, 3, pp. 55-62, 1995

[5] Melo G.F., Lacava P.T., Carvalho J.A., A case study of air enrichment in rotary kiln incineration. Int. Comm. Heat Mass Transfer, 25 (5), pp. 681692, 1998.

[6] Gohlke O., Busch M., Reduction of combustion by-products in WTE plants: $\mathrm{O}_{2}$ enrichment of underfire air in Martin Syncom process. Chemosphere, 42, pp. 545-550, 2001.

[7] Liuzzo G., Verdone N., Bravi M., The benefits of flue gas recirculation in waste incineration. Waste Management, 27, pp. 106-116, 2007.

[8] Iaboni V., De Stefanis P., Aspetti economici del recupero energetico da rifiuti urbani. ENEA, RT/2007/7/ACS Online www.Enea.it, p. 14, 2007. 